\title{
Successful treatment of syphilitic uveitis in HIV-positive patients
}

This article was published in the following Dove Press journal:

Clinical Ophthalmology

19 August 2013

Number of times this article has been viewed

\author{
Mohd-Jamil Nurfahzura ${ }^{1-3}$ \\ Hashim Hanizasurana' \\ Embong Zunaina ${ }^{2,3}$ \\ Hussein Adil',3 \\ 'Department of Ophthalmology, \\ Hospital Selayang, Lebuhraya \\ Selayang-Kepong, Selangor, Malaysia; \\ ${ }^{2}$ Department of Ophthalmology, \\ School of Medical Sciences, Universiti \\ Sains Malaysia, Kelantan, Malaysia; \\ ${ }^{3}$ Hospital Universiti Sains Malaysia, \\ Jalan Raja Perempuan Zainab II, \\ Kelantan, Malaysia
}

\begin{abstract}
We report successful treatment of syphilitic uveitis in a case series of three Human immunodeficiency virus (HIV)-positive patients at Malaysia's Selayang Hospital eye clinic. All three patients with syphilitic uveitis were male, aged from 23 to 35 years old, with a history of high-risk behaviors. Of the patients, two presented with blurring of vision and only one patient presented with floaters in the affected eye. Ocular examination revealed intermediate uveitis (case 1 and case 3 ) and panuveitis (case 2). Each patient showed a high Venereal Disease Research Laboratory (VDRL) titer at presentation and they were also newly diagnosed as HIV positive with variable CD4 counts. All three patients responded well to a neurosyphilis regimen of intravenous penicillin G. At 3 months posttreatment, there was reduction in VDRL titer with improvement of vision in the affected eye. Diagnosis of syphilis needs to be ruled out in all cases of uveitis. All syphilitic uveitis cases should have HIV screening and vice versa, as syphilis is one of the most common infectious diseases associated with HIV-positive patients. Early detection and treatment are important for a good visual outcome.
\end{abstract}

Keywords: syphilitic uveitis, penicillin, neurosyphilis, HIV-positive patient

\section{Introduction}

Syphilis is a multisystem, chronic bacterial infection, caused by the spirochete Treponema pallidum and associated with multiple ocular manifestations. The transmission occurs most often during sexual contact and transplacental infection. Of all uveitis cases worldwide, the incidence of syphilitic uveitis ranged from $1.6 \%$ to $4.5 \%,{ }^{1}$ and can be cured with appropriate antimicrobial therapy, even in patients with HIV coinfection.

\section{Case reports Case I}

A 23-year-old man (homosexual), newly diagnosed as Human immunodeficiency virus (HIV) positive, presented with floaters in both eyes a week prior to presentation, associated with mild eye redness and photophobia that developed a few weeks later. The eye symptoms were preceded by maculopapular rashes over the palms and soles a few months prior (Figure 1). His right-eye vision was 6/90 and left-eye vision was $6 / 60$. Ocular examination revealed both eyes had intermediate uveitis with vitritis and optic disc swelling (Figure 2A). His blood investigation revealed a positive Venereal Disease Research Laboratory (VDRL) test with a dilution of 1:128 and was confirmed with T. pallidum hemagglutination (TPHA) testing. However, his cerebrospinal fluid (CSF)-VDRL test was negative, with no lymphocytic pleocytosis. His CD4 count was 236 cells $/ \mu \mathrm{L}$. He was treated with intravenous penicillin G 4MU 4-hourly for 14 days
Correspondence: Embong Zunaina Department of Ophthalmology, School of Medical Sciences, Universiti Sains Malaysia, 16150 Kubang Kerian, Kelantan, Malaysia Tel +60 97676362

Fax +609765 3370

Email zunaina@kb.usm.my 

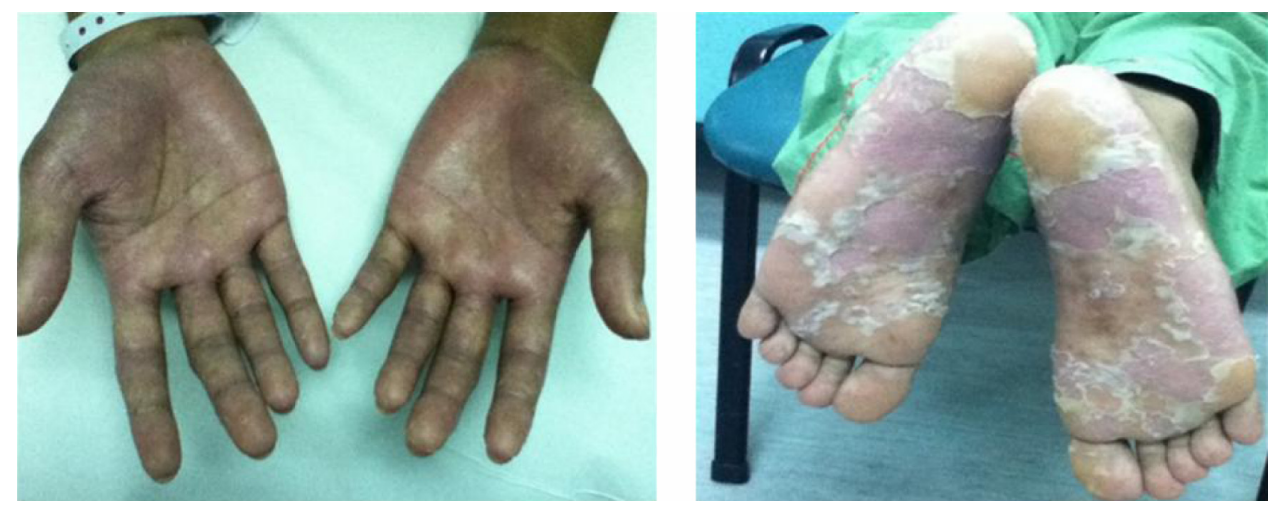

Figure I Case I: maculopapular rashes over both palms (A) and soles (B).

and topical prednisolone 6-hourly for 4 weeks to both eyes. Then the topical prednisolone treatment was tapered down slowly within the next 2 months. He responded well to treatment and, after 3 months of treatment, his VDRL titer reduced to 1:32 (Table 1). The vision of both eyes improved to $6 / 6$ and the fundus showed resolution of disc swelling, intermediate uveitis, and vitritis (Figure 2B).

\section{Case 2}

A 32-year-old man (homosexual) presented with painless blurring of vision in his right eye of a week's duration. His right-eye vision at presentation was hand movement (HM) with dense vitritis (Figure 3A). His ocular symptom was preceded by maculopapular rashes over palms and soles. He was diagnosed to have right-eye panuveitis secondary to syphilis based on a positive VDRL serological test. His HIV screening was also positive, with a CD4 count of 105 cells/ $\mu \mathrm{L}$. His CSF-VDRL was nonreactive with no lymphocytic pleocytosis. He was treated with intravenous penicillin G 4MU 4-hourly for 14 days and topical predni-

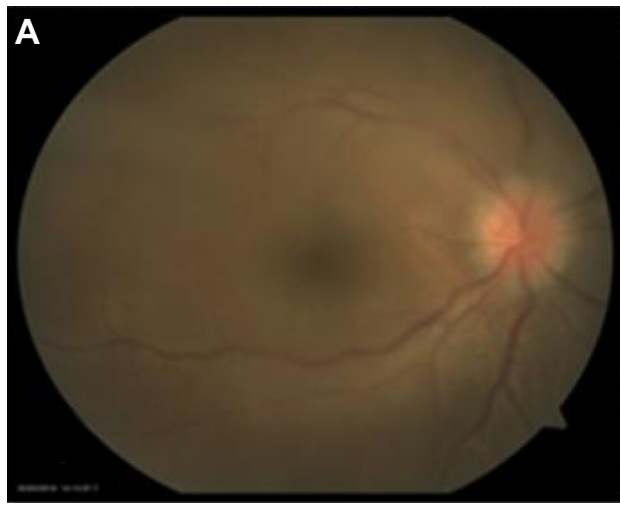

Figure 2 Case I: right-eye images.

Notes: The right eye showed swollen disc with vitritis at presentation $(\mathbf{A})$ and resolution of disc swelling and vitritis at 3 months posttreatment (B).

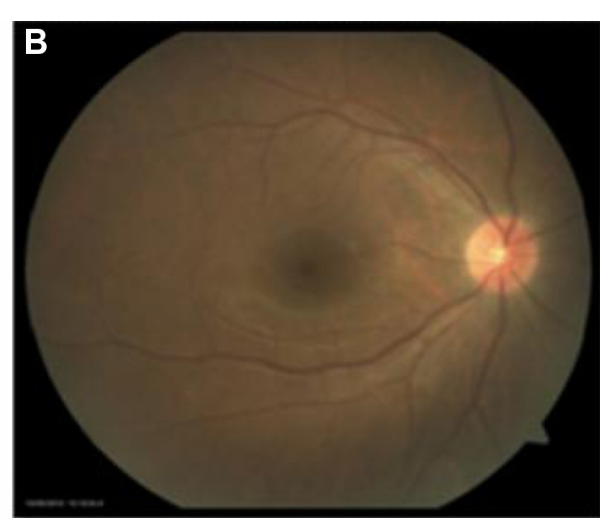

solone 6-hourly for 4 weeks to the right eye. Then the topical prednisolone treatment was tapered down slowly within the next 2 months. He responded well to treatment and his righteye vision improved to $6 / 9$ at 3 months posttreatment. The fundus showed resolved panuveitis with remaining vitreous condensation (Figure 3B). His VDRL titer improved to 1:16 from 1:128 (Table 1).

\section{Case 3}

A 35-year-old man (multiple sexual partners), newly diagnosed as HIV positive and with a CD 4 count of 213 cells $/ \mu \mathrm{L}$, presented with left-eye blurred vision of 2 weeks' duration. He was diagnosed to have intermediate uveitis at a private center and underwent vitrectomy. Immediately after vitrectomy, his vision improved for 1 week but then gradually worsened, and he was referred to us for further management. His left vision was HM. The fundus showed features of intermediate uveitis with presence of snowbanking (Figure 4A). The VDRL and TPHA tests were positive. His CSF-VDRL was nonreactive with no lymphocytic pleocytosis. He was 
Table I Summary of cases with vision and VDRL titer at presentation and at 3 months posttreatment

\begin{tabular}{|c|c|c|c|}
\hline & Case I & Case 2 & Case 3 \\
\hline \multirow[t]{2}{*}{ Biodata } & - 23-year-old male & - 32-year-old male & - 35-year-old male \\
\hline & - Homosexual & - Homosexual & - Multiple sexual partners \\
\hline \multirow[t]{3}{*}{ Ocular symptoms } & - Floaters & - Blurring of vision & - Blurring of vision \\
\hline & - Eye redness & & \\
\hline & - Photophobia & & \\
\hline \multirow[t]{3}{*}{ Features of syphilitic uveitis } & - Intermediate uveitis & - Panuveitis & - Intermediate uveitis \\
\hline & - Vitritis & & \\
\hline & - Disc swelling & & \\
\hline \multirow[t]{2}{*}{ Vision at presentation (affected eye(s)) } & RE: $6 / 90$ & RE: HM & LE: HM \\
\hline & LE: $6 / 60$ & & \\
\hline Vision at 3 months posttreatment & RE: $6 / 6$ & RE: $6 / 9$ & LE: $6 / 9$ \\
\hline (affected eye(s)) & LE: $6 / 6$ & & \\
\hline VDRL titer at presentation & $1: 128$ & $\mathrm{I}: 128$ & $\mathrm{I}: 5 \mathrm{I} 2$ \\
\hline VDRL titer at 3 months posttreatment & $\mathrm{I}: 32$ & $1: 16$ & $\mathrm{I}: 64$ \\
\hline CD4 count (cells $/ \mu \mathrm{L})$ at presentation & 236 & 105 & 213 \\
\hline
\end{tabular}

Abbreviations: HM, hand movement; LE, left eye; RE, right eye; VDRL, Venereal Disease Research Laboratory.

started on intravenous penicillin G 4MU 4-hourly for 14 days and topical prednisolone 6-hourly for 4 weeks to the left eye. Then the topical prednisolone was tapered down slowly within the next 2 months. After 3 months posttreatment, there was improvement of his left-eye vision from HM to 6/9 and the fundus showed resolution of snowbanking (Figure 4B). His VDRL titer reduced to 1:64 from 1:512 (Table 1).

\section{Discussion}

Syphilis is one of the sexually transmitted diseases that is caused by T. pallidum and which commonly occurs in HIVpositive patients. Generally, in syphilis, the typical ocular manifestations are granulomatous anterior uveitis, vitritis, retinitis, choroiditis, retinal vasculitis, neuroretinitis, and macular edema. According to Hughes et al, ${ }^{2}$ the most common ocular manifestation in HIV-positive patients was panuveitis, and other types of ocular findings were anterior
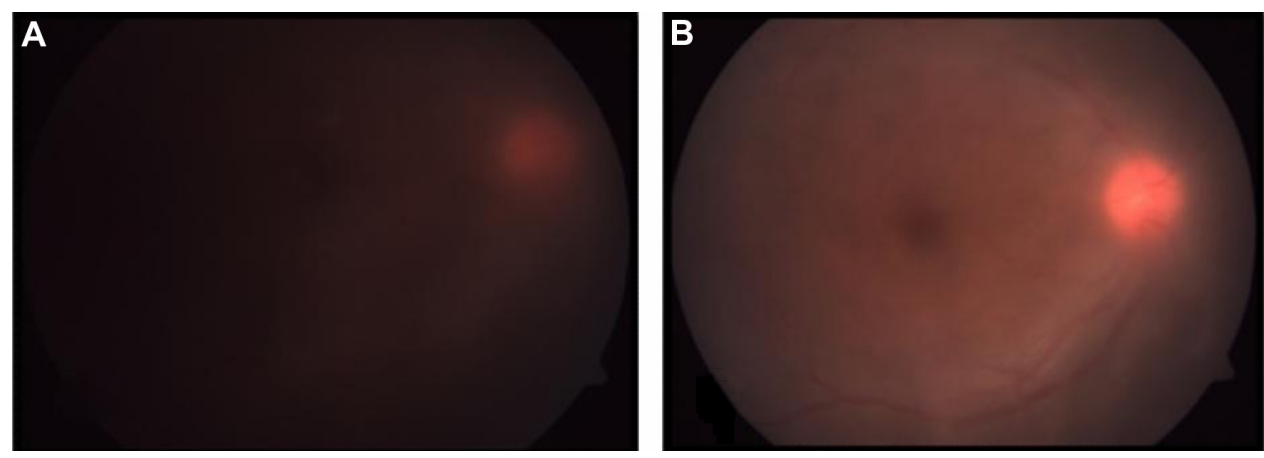

Figure 3 Case 2: right-eye images.

Notes: The right eye at presentation with dense vitritis $(\mathbf{A})$ and improvement of vitritis with remaining vitreous condensation at 3 months posttreatment (B).

uveitis, vitritis, multifocal choroiditis, scleritis, and papillitis Ocular manifestations of syphilis in HIV-infected patients seem to be more severe.

All of our cases were treated with a neurosyphilis regimen of intravenous penicillin G 4MU every 4 hours for 14 days, and all of them responded well. In HIV-positive patients with syphilitic uveitis, the neurosyphilis regimen of the systemic penicillin group should be commenced despite negative CSF results, as the risk of progression to neurosyphilis is high in this type of patient. The recommended neurosyphilis regimen is intravenous penicillin G 3-4MU every 4 hours for 10 to 14 days. ${ }^{3}$ Four-fold reductions of VDRL titer after 3 months indicate a good response to treatment. All of our cases showed a good functional outcome after treatment that was similar to previous studies. ${ }^{4-6}$ Shalaby et $\mathrm{al}^{6}$ reported that HIV-positive patients with syphilitic uveitis were found to have a high prevalence of neurosyphilis. At follow-up of 

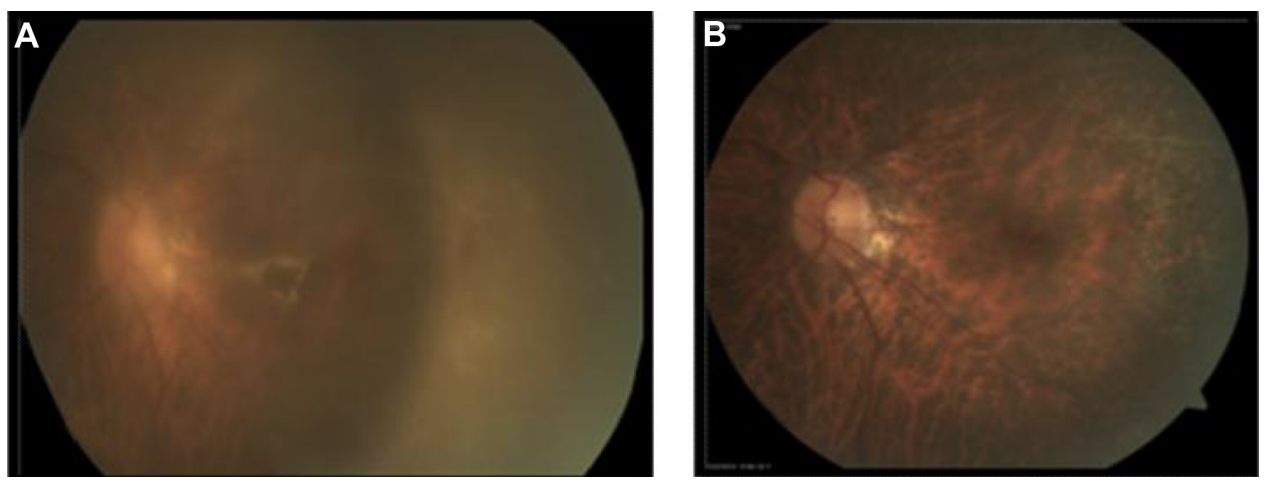

Figure 4 Case 3: left-eye images.

Notes: Intermediate uveitis of the left eye showed presence of snowbanking at presentation (A) and resolution of snowbanking at 3 months posttreatment (B).

$12 \mathrm{HIV}$-infected patients with syphilitic uveitis treated with systemic antimicrobial, 92\% showed decreased intraocular inflammation and visual improvement of $67 \%{ }^{6}$

Close monitoring is mandatory in all HIV cases as they are subject to treatment failure and relapse despite high doses of penicillin. Musher et $\mathrm{al}^{7}$ and Gordon et $\mathrm{al}^{8}$ reported that, even with appropriate antibiotic treatment in HIV-positive patients, there were cases of recurrent or persistent infection. Relapse of infection is more likely in the HIV-positive patient and careful follow-up is required. ${ }^{9}$

\section{Conclusion}

Diagnosis of syphilis needs to be ruled out in all cases of uveitis. All syphilitic uveitis cases should have HIV screening and vice versa, as syphilis is one of the most common infectious diseases associated with HIV-infected patients. Early detection and treatment are important for a good visual outcome.

\section{Disclosure}

The authors report no conflicts of interest in this work.

\section{References}

1. Tait IA. Uveitis due to secondary syphilis. Br J Vener Dis. 1983; 59(6):397-401.

2. Hughes EH, Guzowski M, Simunovic MP, Hunyor AP, McCluskey P. Syphilitic retinitis and uveitis in HIV-positive adults. Clin Experiment Ophthalmol. 2010;38:851-856.

3. Centers for Disease Control and Prevention. Guidelines for treatment of sexually transmitted diseases. MMWR 1998;47(No RR-1):100-118..

4. Liu IH, Chen SJ, Chung YM, Chiou SH, Wong WW. Syphilitic uveitis as the initial manifestation of HIV infection. J Formos Med Assoc. 2002;101(9):642-645.

5. Tran TH, Cassoux N, Bodaghi B, Fardeau C, Caumes E, Lehoang P. Syphilitic uveitis in patients infected with human immunodeficiency virus. Graefes Arch Clin Exp Ophthalmol. 2005;243(9):863-869.

6. Shalaby IA, Dunn JP, Semba RD, Japs DA. Syphilitic uveitis in human deficiency virus-infected patients. Arch Ophthalmol. 1997;115(4): 469-473.

7. Musher DM, Hamill RJ, Baughn RE. Effect of human immunodeficiency virus (HIV) infection on the course of syphilis and on the response to treatment. Ann Intern Med. 1990;113:872-881.

8. Gordon SM, Eaton ME, George R, et al. The response of symptomatic neurosyphilis to high-dose intravenous penicillin $\mathrm{G}$ in patients with human immunodeficiency virus infection. $N$ Engl J Med. 1994;331: 1469-1473.

9. Lynn WA, Lightman S. Syphilis and HIV - a dangerous combination. Lancet Infect Dis. 2004;4:456-466.
Clinical Ophthalmology

\section{Publish your work in this journal}

Clinical Ophthalmology is an international, peer-reviewed journal covering all subspecialties within ophthalmology. Key topics include: Optometry; Visual science; Pharmacology and drug therapy in eye diseases; Basic Sciences; Primary and Secondary eye care; Patient Safety and Quality of Care Improvements. This journal is indexed on Submit your manuscript here: http://www.dovepress.com/clinical-ophthalmology-journal

\section{Dovepress}

PubMed Central and CAS, and is the official journal of The Society of Clinical Ophthalmology (SCO). The manuscript management system is completely online and includes a very quick and fair peer-review system, which is all easy to use. Visit http://www.dovepress.com/ testimonials.php to read real quotes from published authors. 